\title{
EFICIÊNCIA DE UM RETARDANTE DE LONGA DURAÇÃO NA REDUÇÃO DA PROPAGAÇÃO DO FOGO'
}

\author{
Guido Assunção Ribeiro², Gumercindo Souza Lima², Ana Luiza Santos de Oliveira³, Virgínia Londe de \\ Camargos $^{4}$ e Miguel Umbelino Magalhães ${ }^{5}$
}

\begin{abstract}
RESUMO - Os aceiros não naturais têm sido alternativa viável e de amplo uso no meio florestal, nas unidades de conservação e nas margens de rodovias para a redução na propagação do fogo. O seu principal objetivo é o de quebrar a continuidade do material combustível, compartimentalizando a área preferencialmente por grupo de material combustível homogêneo. Com o surgimento de novos produtos e de novos equipamentos de aplicação, os aceiros tradicionais têm sido substituídos por aceiros molhados, aceiros verdes ou aceiros químicos. Dentre as técnicas existentes, o presente trabalho teve por objetivo testar a melhor dosagem de um supressante de fogo, em uma área de pastagem formada pela gramínea Brachiaria decumbens. O supressante utilizado foi o phos-chek, um produto cujo princípio ativo é uma mistura de fosfato de amônio com sulfato de amônio na concentração de $0,134 \mathrm{~kg} / \mathrm{L}$. As dosagens aplicadas foram de 300, 600, 900 e $1.200 \mathrm{~mL} / \mathrm{m}^{2}$. A aplicação foi feita com bomba costal anti-incêndio, em parcelas de 2,0 x 5,0 m, com quatro repetições, utilizando-se o delineamento experimental de parcelas inteiramente ao acaso. Foram medidos o tempo gasto para o fogo queimar a parcela sem o produto; o tempo gasto para o fogo queimar a parcela com o produto; a distância que o fogo avançou na parcela com o produto; e a intensidade de queima, além do monitoramento do tempo, medindo-se a umidade relativa e a velocidade do vento em períodos de uma hora. A linha de fogo demorou cerca de 25 vezes mais tempo para queimar dentro da parcela com o produto, na dosagem de 1.200 $\mathrm{mL} / \mathrm{m}^{2}$, que na parte sem o produto. O fogo queimou toda a parcela na dosagem de $300 \mathrm{~mL} / \mathrm{m}^{2}$, mas o tempo de queima na parte com o produto foi maior que na sem produto. $\mathrm{O}$ phos-chek altera a reação da combustão, retardando o processo de queima e, quanto maior a dosagem, maior o efeito na inibição da reação. A melhor dosagem foi a de $1.200 \mathrm{~mL} / \mathrm{m}^{2}$, mas deve-se estudar o efeito de dosagens entre 900 e $1.200 \mathrm{~mL} / \mathrm{m}^{2}$, para melhorar a relação custo/benefício do uso desse produto.
\end{abstract}

Palavras-chave: Incêndio florestal, retardante de fogo, redução da propagação do fogo e aceiro químico.

\section{EFFICIENCY OF A LONG TERM RETARDANT IN THE REDUCTION OF FIRE PROPAGATION}

\begin{abstract}
Non-natural firebreaks has been an alternative of wide use in forests, conservation units and at road borders to reduce fire propagation. The main objective of these firebreaks is to manage the fuel material, breaking the continuity of the fuel material. With the emergence of new products and equipment, the traditional firebreaks have being replaced by wet, green or chemical firebreaks. The objective of this work was to test the best dose of a fire retardant in a pasture area formed by Bracharia decumbens grass. Phos-chek retardant, a mixture of amonium phosphate and amonium sulphate, was used in the concentration of $0.134 \mathrm{~kg} / \mathrm{L}$. The doses were 300, 600, 900 and 1,200 $\mathrm{ml} / \mathrm{m}^{2}$. The application was carried out with a backpack pump in plots
\end{abstract}

\footnotetext{
${ }^{1}$ Recebido em 20.06.05 e aceito para publicação em 13.09.2006.

${ }_{2}^{2}$ Departamento de Engenharia Florestal da UFV. 36.570-000 Viçosa-MG. E-mail: < gribeiro@ ufv.br>.

${ }^{3}$ Programa de Pós-Graduação em Ciência Florestal da UFV. 36.570-000 Viçosa-MG. E-mail: <anaissa@ yahoo.com.br>.

${ }^{4}$ Programa de Pós-Graduação em Botânica da UFV. 36.570-000 Viçosa-MG. E-mail: <virginialonde @ yahoo.com.br>.

${ }^{5}$ Engenheiro Florestal. E-mail: <miguel@yahoo.com.br>.
} 
of $2 \times 5 \mathrm{~m}$, with four repetitions, using the complete randomized blocks design. The time spent by the fire to burn the plot without the product, time spent by the fire to burn the plot with the product, distance advanced by the fire within the plot with the product, and the burning intensity were measured. Relative moisture and wind speed were measured at one-hour intervals. The fire line took 25 times more to burn the plot with the product, in the plot with $1,200 \mathrm{ml} / \mathrm{m}^{2}$, than the plot without the product. The fire burnt the entire plot with the $300 \mathrm{ml} / \mathrm{m}^{2}$ dose, but the burning time in the plot with the product was larger than that one on the plot without the product. Phos-chek changes the combustion reaction, retarding the burning process and the greater the dose the greater the reaction of inhibition. The best dose was that of $1,200 \mathrm{ml} / \mathrm{m}^{2}$, but further studies are necessary to final out the effects of doses from 900 to $1,200 \mathrm{ml} / \mathrm{m}^{2}$, to improve the cost/benefit rate of product use.

Keywords: Fire retardant, fire propagation reduction, chemical cut fire cleaning, and forest fire.

\section{INTRODUÇÃO}

A proteção contra os incêndios florestais deve ser realizada a partir de diferentes ações envolvendo etapas de prevenção e pré-supressão do fogo. Dentre essas ações, destaca-se o uso de barreiras naturais para a contenção ou redução da propagação do fogo. Nesse contexto, os aceiros construídos surgem como alternativa viável e de amplo uso no meio florestal, nas unidades de conservação, nas margens de rodovias e representam um valioso instrumento em qualquer plano de proteção contra os incêndios florestais.

A redução dos riscos de incêndios florestais na região mediterrânea e a dispersão do fogo são feitos pela compartimentalização das florestas pela construção de uma rede de aceiros. As florestas são separadas por áreas com material combustível reduzido para desacelerar o processo da combustão (COHEN et al., 2002).

Os aceiros baseiam-se no princípio da quebra de continuidade do material combustível, nos sentidos horizontal e vertical em relação à superfície terrestre. Nos primórdios da utilização dessa técnica, a sua construção baseava-se exclusivamente na remoção do material combustível, eliminando um dos elementos essenciais da reação da combustão. Com o surgimento de novos produtos, de equipamentos e de estudos recentes sobre barreiras vegetais (aceiros verdes), o conceito de aceiro foi ampliado. Outras formas de impedimento para a passagem do fogo podem ser utilizadas, a exemplo do emprego de produtos químicos adicionados à água para aumentar a sua eficiência, resultando nos chamados aceiros molhados, ou com o uso de outras formulações químicas que resultam em supressantes de fogo de longa duração.

R. Árvore, Viçosa-MG, v.30, n.6, p.1025-1031, 2006
O emprego de aceiros da forma tradicional tem algumas restrições quando se relaciona a fragilidade do solo com a topografia e com os recursos financeiros disponíveis. Essas variáveis, consideradas isoladamente ou em diferentes combinações, contribuem para a redução de danos ambientais, para o aumento da eficiência do aceiro e para a maximização dos benefícios a custos mais reduzidos. Os custos são um dos principais elementos a serem considerados no manejo do material combustível, sendo importantes a extensão da área manejada e a metodologia empregada (XANTHOPOULOS, 2002).

A eficiência de um aceiro depende da composição da vegetação e da estrutura do material combustível existente em suas proximidades, principalmente pelas características das espécies dominantes, altura e aproximação entre as partículas do combustível. Nesse contexto, vários estratos da vegetação devem ser considerados como árvores, arbustos, plantas herbáceas e serapilheira (RIGOLOT, 2002).

O phos-chek é um retardante de longa duração, cujo princípio ativo é uma mistura de fosfato de amônio com sulfato de amônio. O produto retardante altera a flamabilidade do material combustível, desviando o sentido da reação da combustão quando exposto ao fogo. Na presença do retardante, a liberação dos gases inflamáveis, os quais contribuem com o préaquecimento, combustão em chamas e o conseqüente espalhamento do fogo, não ocorre, pois na presença do produto retardante o material em combustão é transformado diretamente para carvão com liberação de água. A água, ao evaporar, absorve calor, resfriando o combustível e, conseqüentemente, dificultando a continuação da reação da combustão por causa da barreira formada (MONSANTO COMPANY, [200-]. 
O presente estudo teve por objetivo avaliar o efeito do phos-chek sobre a combustibilidade do material combustível e determinar a dosagem mais apropriada desse retardante em uma área de pastagem formada pela gramínea Bachiaria decumbens.

\section{MATERIAL E MÉTODOS}

Os trabalhos de campo para a avaliação do phoschek foram realizados no inverno (agosto de 2003), em plena estação seca, quando a vegetação se encontrava senescente. A pesquisa foi desenvolvida na Central de Ensino e Desenvolvimento Agrário de Florestal CEDAF, no Município de Florestal, Estado de Minas Gerais, vinculada à Universidade Federal de Viçosa, em uma pastagem formada por $B$. decumbens. Essa região está situada no Bioma Cerrado, com temperatura média de $20,1^{\circ} \mathrm{C}$, máxima de $28{ }^{\circ} \mathrm{C}$ e mínima de $13,9^{\circ} \mathrm{C}$. A topografia da região se distribui em $29 \%$ plana, $54 \%$ ondulada e $17 \%$ montanhosa.

Foi empregado o delineamento experimental de parcelas inteiramente ao acaso, com quatro repetições por tratamento. A concentração da calda utilizada foi de $134 \mathrm{~g}$ por litro de água, de acordo com recomendações do fabricante (MONSANTO COMPANY, [200-]. Essa concentração é padrão, variando a quantidade da calda por unidade de área.

Os tratamentos foram representados pela aplicação de $300,600,900$ e $1.200 \mathrm{ml}$ da calda do produto por metro quadrado. As dimensões das parcelas eram de 2 × $10 \mathrm{~m}$, com o seu maior comprimento disposto no sentido do aclive. As dosagens foram aplicadas na metade superior das parcelas $(2 \times 5 \mathrm{~m})$, com uma bomba costal rígida de combate a incêndios, com capacidade de $20 \mathrm{~L}$.

Antes da queima foi feita a coleta do material combustível utilizando o método destrutivo (coleta e pesagem), com o auxílio de um gabarito de $1 \mathrm{~m}^{2}$, de onde se retirou todo o material para pesagem. Uma pequena amostra desse material foi mantido em estufa até peso constante para determinação da quantidade de matéria seca (RIBEIRO e SILVA, 1998) e determinação do poder calorífico. Para cálculo da densidade, a altura da vegetação foi medida no centro da subamostra antes da remoção do material.

A linha de fogo era acesa na extremidade inferior da parcela (sem o produto), de forma que o fogo percorresse no sentido do aclive, na direção do local onde foi aplicado o produto. A medição da distância queimada referiu-se, apenas, à extensão que o fogo adentrou na parte da parcela com o phos-chek. A porção da parcela sem o produto serviu apenas para a linha de fogo se estabelecer. Essa decisão se deveu ao fato de se avaliar quanto o produto contribuiu para impedir ou reduzir o espalhamento do fogo. $\mathrm{O}$ fogo era mantido dentro do perímetro da área desejada, com o auxílio de um aceiro molhado (água com espumógeno), de cerca de 0,50 m de largura, separando os tratamentos.

Durante a queima de cada parcela (tratamento/ repetição) foram realizadas as seguintes medições: umidade relativa, velocidade do vento, tempo gasto para o fogo queimar a parcela sem o produto, tempo gasto para o fogo queimar a parcela com o produto e a distância que o fogo avançou na parcela com o produto.

O Quadro 1 ilustra a distribuição das parcelas e tratamentos em que a área delimitada com linhas duplas indica as parcelas e a porção sombreada, a parte da parcela sem o produto.

A intensidade de queima foi determinada pela equação de Byram (1959). A intensidade de queima permite uma avaliação dos efeitos do fogo na parte aérea da vegetação em níveis mais elevados, tendo em vista a liberação de calor para a atmosfera, com a fórmula $I=H$.w.r, em que I é a intensidade de queima, dada $\mathrm{em} \mathrm{kcal} / \mathrm{m} / \mathrm{s}$; H é o poder calorífico do material combustível dominante, dado em kcal; w é a carga de material combustível disponível, dado em $\mathrm{kg} / \mathrm{m}^{2}$, e r é a velocidade de propagação do fogo, dada em $\mathrm{m} / \mathrm{s}$.

\section{RESULTADOS E DISCUSSÃO}

A carga de material combustível, a sua densidade e a altura da vegetação de cada parcela são mostradas no Quadro 2. É importante ressaltar que todo o material combustível era composto pelo capim-braquiária, pertencendo, portanto, à classe I, segundo a classificação de combustíveis (BROWN, 1974).

A carga de material combustível total é considerada extremamente alta (média de 14,8 t/ha ${ }^{2}$ ), tendo em vista as suas características de tamanho. Todo o material pertence à classe I (material com dimensões menores que $0,6 \mathrm{~cm}$ ). Essa situação foi considerada ideal para comprovar a eficiência do produto, uma vez que as condições eram propícias para gerar uma queima de alta intensidade e semelhante a outra situação encontrada por Ribeiro et al. (2005), em pastagem de braquiária, com carga total de 15,8 t/ha.

R. Árvore, Viçosa-MG, v.30, n.6, p.1025-1031, 2006 
Quadro 1 - Distribuição dos diferentes tratamentos ou concentrações do retardante na área de experimentação Table 1 -Distribution of different treatments or retardant concentrations in the experimental area

\begin{tabular}{|c|c|c|c|c|c|c|c|c|c|}
\hline $\begin{array}{c}900 \\
\mathrm{~mL} / \mathrm{m}^{2}\end{array}$ & $\begin{array}{c}300 \\
\mathrm{~mL} / \mathrm{m}^{2}\end{array}$ & $\begin{array}{c}300 \\
\mathrm{~mL} / \mathrm{m}^{2}\end{array}$ & Controle & $\begin{array}{c}300 \\
\mathrm{~mL} / \mathrm{m}^{2}\end{array}$ & $\begin{array}{c}600 \\
\mathrm{~mL} / \mathrm{m}^{2}\end{array}$ & $\begin{array}{c}900 \\
\mathrm{~mL} / \mathrm{m}^{2}\end{array}$ & $\begin{array}{c}1.200 \\
\mathrm{~mL} / \mathrm{m}^{2}\end{array}$ & $\begin{array}{c}600 \\
\mathrm{~mL} / \mathrm{m}^{2}\end{array}$ & $\begin{array}{c}600 \\
\mathrm{~mL} / \mathrm{m}^{2}\end{array}$ \\
\hline $\begin{array}{l}\text { Área da parcela } \\
\text { sem o produto }\end{array}$ & idem & $\ldots$ & & & & & & & \\
\hline $\begin{array}{c}300 \\
\mathrm{~mL} / \mathrm{m}^{2} \\
\end{array}$ & $\begin{array}{c}1.200 \\
\mathrm{~mL} / \mathrm{m}^{2} \\
\end{array}$ & $\begin{array}{c}900 \\
\mathrm{~mL} / \mathrm{m}^{2} \\
\end{array}$ & $\begin{array}{c}600 \\
\mathrm{~mL} / \mathrm{m}^{2} \\
\end{array}$ & Controle & $\begin{array}{c}1.200 \\
\mathrm{~mL} / \mathrm{m}^{2} \\
\end{array}$ & $\begin{array}{c}1.200 \\
\mathrm{~mL} / \mathrm{m}^{2} \\
\end{array}$ & $\begin{array}{c}900 \\
\mathrm{~mL} / \mathrm{m}^{2} \\
\end{array}$ & Conrole & Controle \\
\hline $\begin{array}{l}\text { Área da parcela } \\
\text { sem o produto }\end{array}$ & idem & $\ldots$ & & & & & & & \\
\hline
\end{tabular}

Quadro 2 - Valores médios da carga de material combustível, altura e densidade em cada parcela Table 2 - Fuel load, fuel height and fuel density means in each plot

\begin{tabular}{cccccccc}
\hline $\begin{array}{c}\text { Matéria úmida } \\
\text { Parcial }(\mathrm{g})\end{array}$ & $\begin{array}{c}\text { Matéria Seca } \\
\text { parcial }(\mathrm{g})\end{array}$ & $\begin{array}{c}(\%) \text { de } \\
\text { Umidade }\end{array}$ & $\begin{array}{c}\text { Total MC úmido } \\
(\mathrm{g}) 0,25 \mathrm{~m}^{2}\end{array}$ & $\begin{array}{c}\text { Total MC seco } \\
(\mathrm{g}) 0,25 \mathrm{~m}^{2}\end{array}$ & $\begin{array}{c}\text { Total MC } \\
\mathrm{seco} \mathrm{t} / \mathrm{ha}\end{array}$ & $\begin{array}{c}\text { Altura } \\
\mathrm{MC}(\mathrm{cm})\end{array}$ & $\begin{array}{c}\text { Densidade } \\
\left(\mathrm{kg} / \mathrm{m}^{3}\right)\end{array}$ \\
\hline Média & 61,61 & 54,72 & 9,50 & 410,10 & 369,43 & 14,78 & 15,87 \\
\hline
\end{tabular}

${ }^{*} \mathrm{MC}=$ material combustível.

A ação do retardante phos-chek se dá sobre a reação da combustão e afeta diretamente o comportamento do fogo, o qual tem no cálculo da intensidade de queima uma das formas mais clássicas para a sua compreensão.

Os resultados das intensidades de queima e as distâncias que o fogo penetrou na parcela com o produto, em diferentes tratamentos (Quadro 3), destacaram o tratamento de $300 \mathrm{ml} / \mathrm{m}^{2}$ e o controle, em que o fogo percorreu toda a extensão da parcela, porém com média de intensidade da linha de fogo maior e desvio-padrão menor na parcela-controle. Esse resultado se encontra dentro do esperado, por indicar uma queima homogênea e de maior intensidade na parcela-controle em relação à parcela com o tratamento, ou seja, apesar de ser uma baixa concentração $\left(300 \mathrm{ml} / \mathrm{m}^{2}\right)$, o produto aplicado alterou a combustão, reduzindo a intensidade de queima.

$\mathrm{O}$ efeito do produto foi marcante à medida que sua concentração aumentou de 300 para $1.200 \mathrm{ml} / \mathrm{m}^{2}$, ou do tratamento $\mathrm{T} 1$ para o tratamento $\mathrm{T} 4$, tanto para a distância queimada quanto para a intensidade de queima (Quadro 3). A intensidade sofreu redução de mais de 15 vezes com o aumento da quantidade do produto por unidade de área. O mesmo ocorreu na distância em que o fogo penetrou na parcela, ou seja, enquanto a parcela do tratamento $\mathrm{T} 1$ foi totalmente queimada; no tratamento T4, o fogo avançou $35 \mathrm{~cm}$, em média.
A combustão em ambiente aberto pode ser considerada um fenômeno turbulento, por estar associado com outras variáveis também turbulentas, como o vento. Esse efeito pode ser observado quando se avalia a variação da intensidade de queima, por meio do desviopadrão. Quanto menor a quantidade do produto por unidade de área (tratamento T1), maiores foram as distâncias queimadas e a intensidade de fogo, indicando que este agiu livremente. Nas maiores concentrações, a queima foi mais homogênea, evidenciando o efeito do produto sobre a reação da combustão.

Ao analisar os números dos Quadros 3 e 4, observouse que os valores da intensidade de queima sempre são maiores na área sem o produto retardante e áreacontrole, seguido das áreas de menor dosagem até as de maior quantidade de produto por metro quadrado. Isso se explica pelo fato de a intensidade de queima ser diretamente proporcional à velocidade do fogo e que, quanto maior a dosagem, menor a velocidade de propagação, evidenciando-se a ação do produto na reação da combustão.

No Quadro 4, apresenta-se a intensidade de queima em cada repetição nos quatro tratamentos, na porção da parcela sem o produto.

Da mesma forma, os dados evidenciam o efeito do produto sobre a redução da intensidade de queima, mesmo no tratamento com menor quantidade de produto (T1), confirmando que a intensidade foi sempre menor 
onde havia o produto comparado com as parcelas sem o produto (Quadro 5). Observou-se, entretanto, que a linha avançou até queimar toda a parcela do tratamento T1. Os dados desse tratamento (Quadro 5) indicaram que toda a parcela foi queimada nas quatro repetições, com o tempo gasto de cerca de 1,7 maior na parte da parcela com o produto. A quantidade aplicada do produto nesse tratamento não foi suficiente para extinguir o fogo como nas dosagens maiores, mas retardou a combustão e, conseqüentemente, aumentou o tempo de espalhamento do fogo.

O fogo gastou o dobro do tempo para queimar as parcelas com o phos-chek em relação às parcelas sem o produto, levando-se em conta que a distância queimada nas parcelas dos tratamentos $\mathrm{T} 1$ ao $\mathrm{T} 4 \mathrm{e}$ diferente (Quadro 3). O fogo durou, em média, 116 seg para queimar os $500 \mathrm{~cm}$ da parcela sem o produto (tratamento T4) e $192 \mathrm{seg}$ para queimar cerca de 34 $\mathrm{cm}$ da parcela com o produto. Isso resulta numa relação de 4,3 e $0,17 \mathrm{~cm} / \mathrm{seg}$, respectivamente, significando que, em termos relativos, o fogo gastou 25 vezes mais tempo para queimar a mesma distância da parcela com o produto, em comparação com à parcela sem o produto.
Essa relação teve valores mais próximos no tratamento $\mathrm{T} 1$, ou seja, nas parcelas sem o produto o fogo queimou $3,9 \mathrm{~cm} \cdot \mathrm{seg}^{-1}$ e com o produto, $2,16 \mathrm{~cm} . \mathrm{seg}^{-1}$, levando apenas $1,8 \mathrm{vez}$ mais tempo para queimar a mesma distância na parcela com o produto em relação à parcela sem o produto.

Apenas a variável tempo de queima foi nãosignificativa, ou seja, não sofreu influência dos tratamentos (ou do produto). O tempo de queima corresponde ao tempo que a combustão durou ao longo da parcela onde foi aplicado o produto. Provavelmente, outras variáveis, como heterogeneidade na aplicação do produto, podem ter contribuído para uma grande variação dos dados, resultando, conseqüentemente, na não-significância da análise de variância.

O teste de média, das variáveis indica que foram significativas o peso de material de combustível consumido, a velocidade do fogo durante a queima na parcela com o produto e a distância de queima, ou seja, a distância que o fogo percorreu ao longo da parcela com o produto (Quadro 6).

Quadro 3 - Intensidade de queima $(\mathrm{kcal} / \mathrm{m} / \mathrm{s})$ e distância $(\mathrm{cm})$ que a combustão avançou para dentro da parcela com o phoschek

Table 3 - Burning intensity $(\mathrm{kcal} / \mathrm{m} / \mathrm{s})$ and burned distance $(\mathrm{cm})$ on the plot with phos-chek

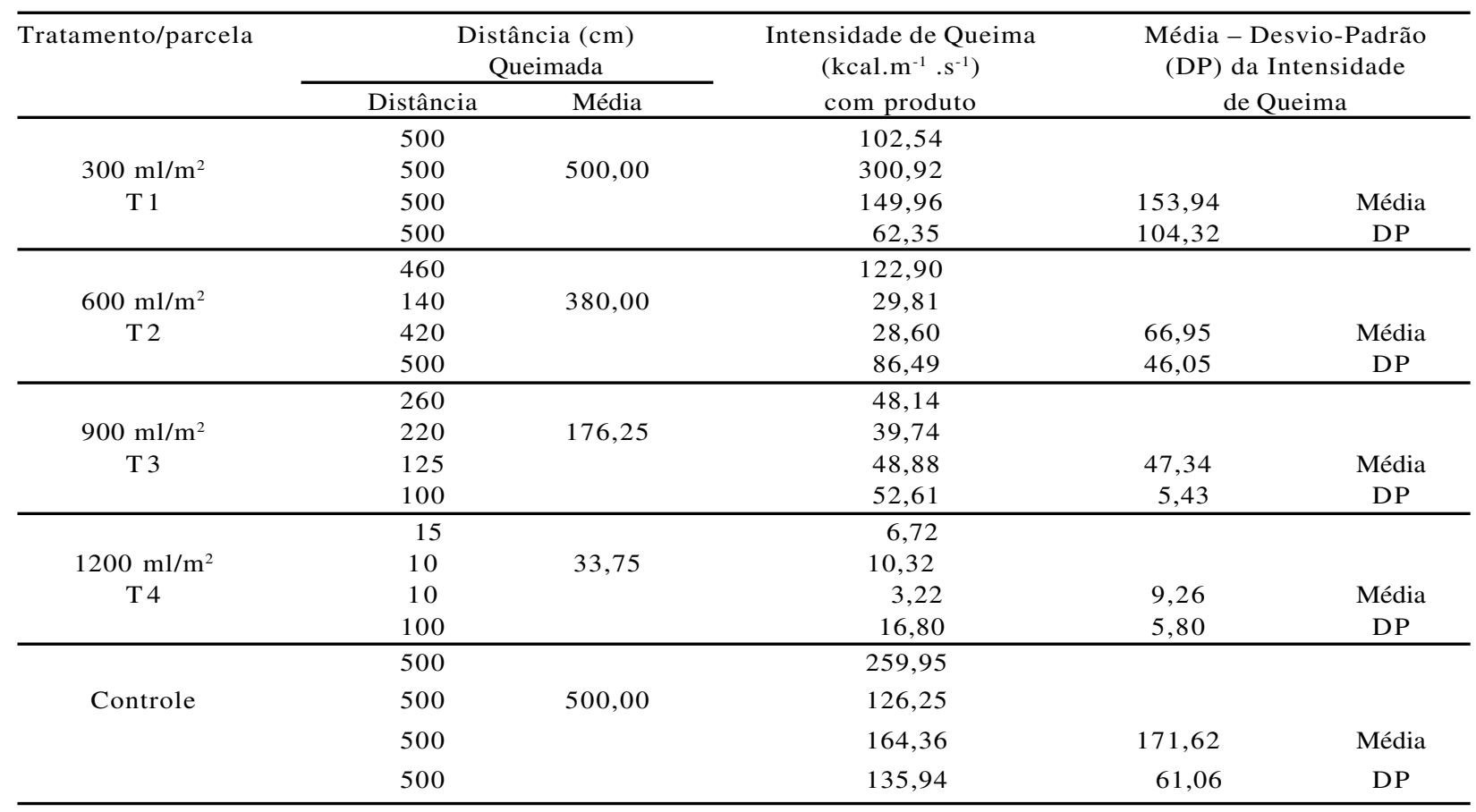


Quadro 4 - Intensidade de queima ( $\mathrm{kcal} / \mathrm{m} / \mathrm{s})$, média e desvio-padrão para cada repetição dos quatro tratamentos, na parte da parcela sem o produto supressante

Table 4 - Burning intensity $(\mathrm{kcal} / \mathrm{m} / \mathrm{s})$, mean and standard deviation for each repetition of the four treatments, in the plot without phos-chek

\begin{tabular}{|c|c|c|c|c|c|c|}
\hline \multirow[b]{2}{*}{ Repetição } & \multicolumn{6}{|c|}{ Intensidade de Queima sem Produto $(\mathrm{kcal} / \mathrm{m} / \mathrm{s})$} \\
\hline & $\mathrm{T} 1$ & $300 \mathrm{~mL} / \mathrm{m}^{2}$ & $\mathrm{~T} 2600 \mathrm{~mL} / \mathrm{m}^{2}$ & T3 $900 \mathrm{~mL} / \mathrm{m}^{2}$ & $\mathrm{~T} 41200 \mathrm{~mL} / \mathrm{m}^{2}$ & Controle \\
\hline 1 & & 222,99 & 249,49 & 275,93 & 151,68 & 306,36 \\
\hline 2 & & 506,50 & 248,43 & 231,54 & 431,10 & 234,84 \\
\hline 3 & & 280,25 & 113,73 & 173,53 & 207,30 & 278,24 \\
\hline 4 & & 99,17 & 196,39 & 315,99 & 316,11 & 273,86 \\
\hline Média & & 277,23 & 202,01 & 249,25 & 276,55 & 273,33 \\
\hline Desvio-padrão & & 170,51 & 63,86 & 61,14 & 123,61 & 29,42 \\
\hline
\end{tabular}

Quadro 5 - Intensidade de queima (kcal/m/s) e tempo de queima para cada parcela/tratamento na parte da parcela "com" e "sem" phos-chek

Table 5 - Burning intensity $(\mathrm{kcal} / \mathrm{m} / \mathrm{s})$, and burning time for each plot/treatment in the plot with and without phos-chek

\begin{tabular}{cccccc}
\hline Tratamento & Estatística & $\begin{array}{c}\text { Tempo T } \\
\text { (segundo) } \\
\text { Sem Produto }\end{array}$ & $\begin{array}{c}\text { Tempo T } \\
\text { (segundo) } \\
\text { Com Produto }\end{array}$ & $\begin{array}{c}\text { Intensidade } \\
\text { de queima Sem } \\
\text { Produto(kcal/m/s) }\end{array}$ & $\begin{array}{c}\text { Intensidade } \\
\text { de queima Com } \\
\text { Produto (kcal/m/s) }\end{array}$ \\
\hline $300 \mathrm{~mL} / \mathrm{m}^{2}$ & Média & 129,75 & 232,25 & 277,23 & 153,94 \\
$\mathrm{~T} 1$ & Desvio Padrão & 43,22 & 56,42 & 170,51 & 104,32 \\
$600 \mathrm{~mL} / \mathrm{m}^{2}$ & Média & 135,00 & 232,75 & 202,01 & 66,95 \\
$\mathrm{~T} 2$ & Desvio Padrão & 33,33 & 123,94 & 63,86 & 46,05 \\
$900 \mathrm{~mL} / \mathrm{m}^{2}$ & Média & 150,50 & 245,50 & 249,25 & 57,34 \\
$\mathrm{~T} 3$ & Desvio Padrão & 59,29 & 55,87 & 61,14 & 9,43 \\
$1200 \mathrm{~mL} / \mathrm{m}^{2}$ & Média & 116,25 & 192,00 & 276,55 & 5,26 \\
$\mathrm{~T} 4$ & Desvio Padrão & 35,80 & 173,83 & 123,61 & 171,62 \\
Controle & Média & 140,00 & 236,00 & 273,32 & 61,06 \\
\hline
\end{tabular}

Quadro 6 - Teste de Tukey $(\mathrm{p}<0,05)$ para as variáveis significativas na análise de variância

Table $6-$ Tukey test $(p<0.05)$ for the significant variables in the variance analysis

\begin{tabular}{|c|c|c|c|c|}
\hline Tratamento & Intensidade de queima & Peso de $\mathrm{MC}^{1}$ consumido & Velocidade de queima & Distância queimada \\
\hline 4 & $2,056948 \quad a$ & $-0,256909 \quad a$ & $-6,59104$ & 0,3375 a \\
\hline 3 & $3,852214 \quad b$ & $2,056450 \quad b$ & $-4,99178$ & 1,7625 a \\
\hline 2 & $4,004943 \mathrm{~b}$ & $2,479660 \quad b$ & $-4,52727$ & $3,8000 \mathrm{~b}$ \\
\hline 1 & $4,870027 \quad b$ & $3,016618 \quad b$ & $-3,81647$ & $5,0000 \mathrm{~b}$ \\
\hline
\end{tabular}

- Valores seguidos de mesma letra não diferem, estatisticamente, pelo teste de Tukey a $5 \%$.

- ${ }^{1} \mathrm{MC}=$ material combustível.

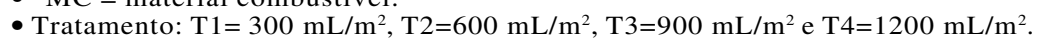

A intensidade de queima e a quantidade de material combustível consumido tiveram comportamento semelhante diante dos tratamentos ou das diferentes dosagens utilizadas, sendo que o tratamento 4 (1200 $\mathrm{ml} / \mathrm{m}^{2}$ ) diferiu dos demais a $5 \%$ de probabilidade e os demais não apresentaram diferença significativa.

O mesmo aconteceu para a quantidade de material combustível consumido. O tratamento com maior dosagem diferiu dos demais, ou seja, o retardante contribuiu para o menor consumo de material combustível.
A velocidade de queima apresentou resultados diferentes dos anteriores, destacando-se o tratamento com maior quantidade do produto por metro quadrado (T4), o qual foi estatisticamente diferente dos demais. Entretanto, o tratamento 3 foi semelhante ao 2 e este, igual ao 1 . Um fator marcante, que pode ter interferido nessa variável, é a velocidade do vento. Essa variável tem influência determinante na dispersão do fogo, em qualquer circunstância na qual a combustão ou a queima esteja ocorrendo. 
A última variável utilizada para auxiliar na determinação da melhor dosagem do produto, por unidade de área, foi a distância que o fogo percorreu na parcela com o produto. O resultado indica uma semelhança entre as duas maiores dosagens, as quais diferiram estatisticamente das duas menores. Essa variável também sofreu influência da corrente do vento e, possivelmente, da falta de homogeneidade na aplicação do produto.

\section{CONCLUSÃO}

O produto phos-chek retarda a taxa de inflamabilidade. A dosagem de $1.200 \mathrm{ml} / \mathrm{m}^{2}$ apresentou melhores resultados na intensidade de queima, peso de material combustível consumido e velocidade de queima. Entretanto, os dados não permitiram estimar, por análise de regressão, por exemplo, se as dosagens entre 900 e $1.200 \mathrm{ml} / \mathrm{m}^{2}$ poderiam ter efeitos semelhantes. Assim, outros estudos devem ser realizados com vistas a encontrar dosagens menores com o objetivo de reduzir a relação custo/benefício.

\section{AGRADECIMENTOS}

Ao Prof. José Elias Saad Rezende, ex-diretror da Central de Ensino e Desenvolvimento Agrário de Florestal - CEDAF, e à equipe técnica da Guarany Indústria e Comércio Ltda., pelo apoio na realização dos trabalhos de campo; e à Companhia Energética de Minas Gerais - CEMIG, pelo apoio financeiro, através do Convênio de Cooperação Técnica firmado com a Sociedade de Investigações Florestais - SIF, dentro do Programa de Pesquisa e Desenvolvimento da Agência Nacional de Energia Elétrica - ANEEL.

\section{REFERÊNCIAS BIBLIOGRÁFICAS}

BYRAM, G.M. Combustion of forest fuels. In: DAVIS, K.P. Forest fire - control and use. New York : Mc Graw Hill, 1959. p. 77-84.

COHEN, M.; RIGOLOT, E.; ETIENNE, M. Modelling fuel distribution with cellular-automata for fuel-break assessment. In: VIEGAS, D.X.

Forest Fire Research \& Wildland fire Safety. Luso, Coimbra: 2002. p. 72.
GRODZKI, L. Efeitos do fogo sobre o microclima de um sistema agroflorestal de bracatinga (Mimosa scabrella Benth). 2000. 129 f. Tese (Doutorado em Engenharia Florestal) Universidade Federal do Paraná, Curitiba, 2000.

LIMA, G. S. Os incêndios florestais no Estado de Minas Gerais. Ação Ambiental, v. 2, n. 12 , p. 15-18, 2000.

MONSANTO COMPANY. Phos-chek: fire retardant in prescribed burning - Application guide. Publication number 9185 Supersedes IC/FP-202 A. [200-].

PYNE, S. J. Introduction to wild land

fire. Fire management in the United States. New York : John Wiley \& Sons, 1984. 455 p.

RIBEIRO, G. A.; BONFIM, V. R. Incêndio Florestal versus queima controlada. Ação Ambiental, v. 2 , n. 12 , p. 8-11, 2000.

RIBEIRO, G. A. et al. Barreiras vegetais na redução da propagação dos incêndios florestais. In: I CONGRESSO DE INOVAÇÃO TECNOLÓGICA EM ENERGIA ELÉTRICA CITENEL, 1.; 2005, Brasília, Agencia Nacional de Energia Elétrica. Anais... 2005 (no prelo).

RIBEIRO, G. A.; SILVA, J. C. Estudo comparativo de dois métodos de inventário de material combustível. In: SEMINÁRIO SUL-AMERICANO, 1.; REUNIÃO CONJUNTA SIF/FUPEF/IPEF, 5.; sobre Controle de Incêndios Florestais ( $1^{\circ}$ e $5^{a}: 1998$ : Belo Horizonte). Anais ... Viçosa, MG: Sociedade de Investigações Florestais, DEF/UFV, 1998. p. 362-371.

RIGOLOT, E. Fuel-break assessment with an expert appraisement approach. In: VIEGAS, D. X. Forest Fire Research \& Wildland fire Safety. Luso, Coimbra: 2002. p. 72.

XANTHOPOULOS, G. Shrub removal cost estimation for fire hazard reduction in Mediterranean Forest condition. In: VIEGAS, D.X. Forest Fire Research \& Wildland fire Safety. Luso, Coimbra, Portugal, novembro de 2002. p. 33. 